Pacific Journal of Mathematic 


\title{
SPACES OF WEAKLY CONTINUOUS FUNCTIONS
}

\author{
JUAN FERRERA
}

In this paper we study some properties about the space of weakly continuous functions on bounded sets of a Banach space $E: C_{w b}(E)$. We study the relation between $C_{w b}(E)$ and $C_{w b u}(E)$ (weakly uniformly continuous functions on bounded sets). And we give the following characterization: $C_{w b u}(E)$ is a barreled space if and only if $E$ is reflexive.

o. Notation and preliminaries. Throughout this paper $E$ will represent a real Banach space and $B_{n}$ the closed ball of radius $n$. The basic definitions of locally convex spaces and their properties are explained in [6]. We will say that a Banach space is weakly compactly generated $(W C G)$, when it has a weakly compact total subset. Both separable and reflexive spaces are particular cases of $W C G$ spaces. For further information, see [2].

For the topological concepts that are used, we will follow [5]. We will say that a completely regular topological space is realcompact when each $z$-ultrafilter with the countable intersection property has an nonempty intersection. A subset of a topological space will be relatively pseudocompact when every real-valued continuous function defined on the space is bounded on the subset.

We will define the $b w$-topology on $E$ as the finest which agrees with the weak topology on bounded subsets of $E$. A subset will be $b w$-closed (respectively bw-open) if and only if it is weakly closed (respectively relatively open) when it is restricted to each $B_{n}$.

If $X$ is a topological space, $C(X)$ will represent the space of real-valued continuous functions on $X$. Except for when indicating the opposite, we will give $C(X)$ the compact-open topology, defined by the family of semi-norms

$$
P_{K}(f)=\operatorname{Sup}_{x \in K}|f(x)|
$$

when $K$ ranges over the compact subsets of $X . C_{w b}(E)$ will represent the space of real functions which are weakly continuous when restricted to the bounded subsets of $E . C_{w b u}(E)$ will be the space of real functions which are weakly uniformly continuous when restricted to the bounded subsets of $E$.

$C_{w b u}(E) \subset C_{w b}(E)$, if we give the topology of the uniform convergence on weakly compact subsets to both, we will have that $C_{w b u}(E)$ is a subspace of the locally convex space $C_{w b}(E)$.

1. The space $C_{w b}(E)$. The space $E$ endowed with the $b w$-topo- 
logy will be represent by $X$. It is evident that $C_{w b}(E)$ coincides with $C(X)$ as sets. On the other hand, the weak compacts of $E$ and the compacts of $X$ are the same (by being bounded). Therefore, both spaces are topologically isomorphic.

We are concerned with studying the properties of $C_{w b}(E)$, for which we need the following lemma:

LEMma 1.1. If $E$ is a weakly normal space, then $X$ is normal and hence completely regular.

Proof. If $E$ is a weakly normal space, then for every $n, B_{n}$ endowed with the weak restricted topology is normal.

Let $C$ and $F$ be closed subsets of $X, C \cap F=\varnothing$.

$C_{n}=C \cap B_{n}, \quad F_{n}=F \cap B_{n} . \quad C_{1}$ and $F_{1}$ are weakly closed. By Urysohn's lemma, we have $f_{1}: B_{1} \rightarrow[0,1]$ weakly continuous function such that:

$$
f_{1}\left(C_{1}\right)=\{0\} \text { and } f_{1}\left(F_{1}\right)=\{1\}
$$

will be $f_{2}^{*}: B_{1} \cup C_{2} \cup F_{2} \rightarrow[0,1]$ defined by

$$
\left.f_{2}^{*}\right|_{B_{1}}=f_{1}, f_{2}^{*}\left(C_{2}\right)=\{0\}, f_{2}^{*}\left(F_{2}\right)=\{1\} \text {. }
$$

This function is weakly continuous and it is defined on a weakly closed subset of $B_{2}$, therefore, by Tietze's theorem, it can be extended to another function $f_{2}: B_{2} \rightarrow[0,1]$ weakly continuous and such that

$$
f_{2}\left(C_{2}\right)=\{0\} \text { and } f_{2}\left(F_{2}\right)=\{1\} \text {. }
$$

We define by induction $f_{n}: B_{n} \rightarrow[0,1]$ weakly continuous such that:

$$
f_{n}\left(C_{n}\right)=\{0\}, f_{n}\left(F_{n}\right)=\{1\} \text {, and }\left.f_{n}\right|_{B_{n-1}}=f_{n-1} .
$$

We define $f(x)=f_{n}(x)$ if $x \in B_{n}$.

We have that $f$ is continuous on $X, f(C)=\{0\}$ and $f(F)=\{1\}$. Hence $X$ is normal.

Unfortunately we have not a general result, eliminating the hypotheses of weak normality, which affirms that $X$ is always a completely regular; which is necessary for the study of $C(X)$. Nevertheless, if $E$ endowed with the coarser topology that makes the functions of $C_{w b}(E)$ continuous, is represented by $\widetilde{X}$, we achieve that the above space is completely regular, and we have that the following inclusions are continuous:

$$
X \longrightarrow \tilde{X} \longrightarrow\left(E, \sigma\left(E, E^{\prime}\right)\right)
$$


giving equality to the first inclusion if and only if $X$ is completely regular.

We proceed to study the properties of $C_{w b}(E)$. In the first place we will see when it is a bornological space. According to Nachbin-Shirota's theorem [7.8], this would be equivalent to $X$ being realcompact. We have the following statement:

THEOREM 1.2. If $E$ is weakly normal, then $C_{w b}(E)$ is bornological if and only if $E$ is weakly realcompact.

Proof. Simply by noting the fact that the $B_{n}$ balls with weak restricted topology are realcompacts, it follows that $X$ (respectively $E$ ) is realcompact (respectively weakly realcompact), we will do the proof for $E$, but with light modifications serving for $X$.

Let $\left\{U_{\alpha}\right\}_{\alpha \in A}$ be a $z$-ultrafilter. Each $U_{\alpha}=f_{\alpha}^{-1}(0)$ with $f_{\alpha}: E \rightarrow R$ weakly continuous.

We have that for every index sequence $\left(\alpha_{n}\right) \in A, \bigcap_{n=1}^{\infty} U_{\alpha_{n}} \neq \varnothing$.

(1) There is $n_{0}$ such that $U_{\alpha} \cap B_{n_{0}} \neq \varnothing$ for every $\alpha \in A$.

If it were not like this, for each $n \in N$ we would have $\alpha_{n} \in A$ such that $U_{\alpha_{n}} \cap B_{n}=\varnothing$. With which we would have that $\bigcap_{n=1}^{\infty} U_{\alpha_{n}}=$ $\varnothing$, failing the countable intersection property.

Therefore, for every $n \geqq n_{0}\left\{U_{\alpha} \cap B_{n}\right\}_{\alpha \in A}$ is a filter basis in $B_{n}$.

(2) There exists $n_{1} \geqq n_{0}$ in such a way that the filter basis $\left\{U_{\alpha} \cap B_{n_{1}}\right\}_{\alpha \in A}$ has the countable intersection property.

Supposing the above fails: for every $n \geqq n_{0}$ there would be $\left\{\alpha_{n, m}\right\}_{m \in N}$ index sequence in such a way that $\bigcap_{m=1}^{\infty}\left(U_{\alpha_{n, m}} \cap B_{n}\right)=\varnothing$. The countable family $\left\{U_{\alpha_{n, m}}\right\}_{n, m \in N, n \geq n_{0}}$ has an empty intersection contrary to the countable intersection property.

(3) $\left\{U_{\alpha} \cap B_{n_{1}}\right\}_{\alpha \in A}$ is the basis of a $z$-filter with the countable intersection property in $B_{n_{1}}$, because $\left.f_{\alpha}\right|_{B n_{1}}$ is a continuous function on $B_{n_{1}}$ endowed with the weak topology restricted, for every $\alpha \in A$.

(4) $\left\{U_{\alpha} \cap B_{n_{1}}\right\}_{\alpha \in A}$ is a basis for a $z$-ultrafilter.

If not, it would be $Z \in B_{n_{1}}$ zero in $B_{n_{1}}$, that is, $Z=f^{-1}(0)$ with $f$ weakly continuous on $B_{n_{1}}$, in such a way that $Z \cap U_{\alpha} \cap B_{n_{1}} \neq \varnothing$ for every $\alpha \in A$, but $Z$ not containing any $U_{\alpha} \cap B_{n_{1}}$. But since $B_{n_{1}}$ is a weakly closed subset of $E$, by normality there exists $\widetilde{f}: E \rightarrow R$ weakly continuous, such that $\left.\tilde{f}\right|_{B n_{1}}=f$. Furthermore, $\tilde{f}^{-1}(0)=\widetilde{Z}$ will be a zero of $E$ (with the weak topology), and $Z=\widetilde{Z} \cap B_{n_{1}}$. But $\widetilde{Z} \cap U_{\alpha} \neq \varnothing$ for every $\alpha \in A$, hence $\widetilde{Z}=U_{\alpha_{0}}$ for some $\alpha_{0}$ by being $z$-ultrafilter, then $Z=U_{\alpha_{0}} \cap B_{n_{1}}$.

Just as by hypothesis $B_{n_{1}}$ is realcompact, it follows that $\bigcap_{\alpha \in A} U_{\alpha} \cap B_{n_{1}} \neq \varnothing$ and thus $\bigcap_{\alpha \in A} U_{\alpha} \neq \varnothing$. Hence $E$ is weakly realcompact.

Since $\tilde{f}$ is also continuous on $X$, it can also be inferred that $X$ 
is realcompact.

We have then that $\widetilde{X}=X$ is realcompact if and only if $E$ is weakly realcompact, and that $C_{w b}(E)$ is bornological if and only if $E$ is weakly realcompact.

Weakly realcompact Banach spaces are described in [1]. Nevertheless, there exists weakly realcompact spaces which are not weakly normal, as in the case of $l^{\infty}[1, p .12]$. In any case, the class of weakly normal and weakly realcompact spaces is wide; particularly every $W C G$ space is weakly Lindelöf [9] and thus is in our hypotheses.

The following statement gives a partial answer to the problem for the case of not necessarily normal spaces.

THEOREM 1.3. If $E$ is the dual of a separable space, then $C_{w b}(E)$ is bornological; in particular $C_{w b}\left(l^{\infty}\right)$ is bornological.

Proof. Let $E=F^{\prime}$ be. $\left\{x_{n}\right\}_{n \in N}$ a dense subset of $F$. We define:

$$
\begin{aligned}
f: \widetilde{X} & \longrightarrow R^{N} \\
& x^{\prime} \longrightarrow\left(\left(x_{n}, x^{\prime}\right)\right)_{n} .
\end{aligned}
$$

This map is one to one because $\left\{x_{n}\right\}_{n \in N}$ separates points of $E$ by being dense in F. Furthermore, $f$ is continuous by being $f=\tilde{f} \circ i$, being $i: \widetilde{X} \rightarrow E$ continuous and $\widetilde{f}: E \rightarrow R^{N}$ continuous, given that $\widetilde{f}$ composed with $p_{n}: R^{N} \rightarrow R$ is $x_{n}$. Since $R^{N}$ is realcompact and all its subsets are as well (by the points being $G_{\dot{\delta}}$-sets), we have, because of [4], that $\widetilde{X}$ is realcompact and $C_{w b}(E)$ is bornological.

Finally we are going to see that $\tilde{X}$ is a NS-space. That is, every relatively pseudocompact and closed subset is compact. Through [7] we achieve that $C_{w b}(E)$ is always barreled.

Proposition 1.4. $C_{w b}(E)$ is barreled.

Proof. Let $K \subset \widetilde{X}$ be a relatively pseudocompact and closed subset. For all $x^{\prime} \in E^{\prime}, x^{\prime}(K)$ is bounded, hence $K$ is weakly bounded and thus bounded. Furthermore, $K \subset B_{n}$ for some $n$, from where it follows that $K$ is weakly closed. As on the other hand each weakly continuous function on $E$ is continuous on $\tilde{X}$, we have that $K$ is weakly relatively pseudocompact. Also through [10] we achieve that $K$ is weakly compact and thus compact in $\tilde{X}$.

2. The space $C_{w b u}(E)$. First of all, we will study the relationship between $C_{w b u}(E)$ and $C_{w b}(E)$.

Proposition 2.1. $C_{w b u}(E)$ is a dense subspace of $C_{w b}(E)$. 
Proof. Let $f$ be a function of $C_{w b}(E)$. For every weakly compact subset $K$ of $E,\left.f\right|_{K}$ will be weakly continuous. Let $\widetilde{f}_{K}$ be an extension to the Stone-Cech compactification of $E$ endowed with the weak topology, $\beta(E)$, which will be uniformly continuous. Then $f_{K}=\left.\tilde{f}_{K}\right|_{E}$ is weakly uniformly continuous on $E$. Then $f_{K} \in C_{w b u}(E)$ for every weakly compact subset $K$.

Obviously, $\left\{f_{K}\right\}_{K}$ is a net that converges uniformly on weakly compact subsets of $E$, to $f$.

Proposition 2.2. $\quad C_{w b u}(E)=C_{w b}(E)$ if and only if $E$ is reflexive.

Proof. If $E$ is reflexive, the equality holds because the balls are weakly compacts.

Conversely given $f$ weakly continuous on $E$, we do have that $f \in C_{w b}(E)=C_{w b u}(E)$. Then $f$ is weakly uniformly continuous on $B_{1}$ and consequently it is bounded on $B_{1}$, because it is totally bounded. Since $f$ is weakly uniformly continuous on $B_{1}$, it follows that there exists a weak neighborhood of zero, $V$; such that $|f(x)-f(y)|<1$ provided that $x-y \in V$ and $x, y \in B_{1}$. Since $B_{1}$ is weakly totally bounded, we infer that there exists $x_{1}, \cdots, x_{n_{0}} \in B_{1}$ such that

$$
B_{1} \subset \bigcup_{i=1}^{n_{0}}\left\{x_{i}+V\right\}
$$

Thus for every $x \in B_{1}$

$$
|f(x)| \leqq \operatorname{Max}_{i=1, \cdots, n_{0}}\left\{\left|f\left(x_{i}\right)\right|+1\right\} .
$$

This means that every weakly continuous function over $E$ is bounded on $B_{1}$, hence $B_{1}$ is weakly relatively pseudocompact, and weakly closed. By [10] it follows that $B_{1}$ is weakly compact and thus $E$ reflexive.

The proof of this proposition suggest that, if $E$ is not reflexive, one method to find a function which belongs to $C_{w b}(E)$ and does not belong to $C_{w b u}(E)$, it would be to find a weakly continuous fuuction over $E$ which is not bounded on $B_{1}$.

EXAMPLE 2.3. If $E$ is a nonreflexive separable space, the JamesKlee theorem [2, p. 7] states there exists $\phi \in E^{\prime}$ which does not attain its norm.

We define the function

$$
f_{0}: B_{1} \longrightarrow R \text { by } f_{0}(x)=\frac{1}{\|\phi\|-\phi(x)} .
$$

This function is weakly continuous on $B_{1}$, and is not bounded. Since $E$ is a separable space, then it is $W C G$ and therefore weakly normal. 
Thus by Tietze's theorem there exists $f$ weakly continuous on $E$, which extends $f_{0}$, and which is not bounded on the unit ball; therefore it can not belong to $C_{w b u}(E)$.

CoROllary 2.4. $C_{w b u}(E)$ is complete if and only if $E$ is reflexive.

Proof. If $E$ is reflexive, $C_{w b}(E)=C_{w b u}(E)$ and also $C_{w b}(E)$ is complete by [3]. Thus $C_{w b u}(E)$ is complete.

Conversely, since $C_{w b u}(E)$ is dense in $C_{w b}(E)$, if it is complete, both spaces have to be the same and because of that it is reflexive.

THEOREM 2.5. $\quad C_{w b u}(E)$ is barrelled if and only if $E$ is reflexive.

Proof. If $E$ is reflexive $C_{w b u}(E)=C_{w b}(E)$ and consequently barrelled. Conversely we consider the following diagram:

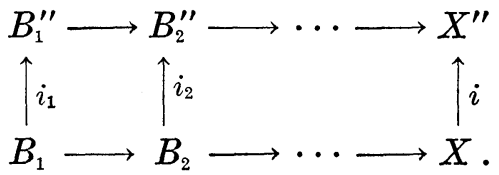

$B_{n}^{\prime \prime}$ are endowed with the weak star topology restricted. $X^{\prime \prime}$ will be the inductive limit of the spaces $B_{n}^{\prime \prime}$.

$i$ is continuous because when composed with the inclusions $j_{n}: B_{n} \rightarrow X$ it follows that $i \circ j_{n}=j_{n}^{*} \circ i_{n}$, been $j_{n}^{*}: B_{n}^{\prime \prime} \rightarrow X^{\prime \prime}$ the canonical inclusion in the inductive limit; obviously $j_{n}^{*} \circ i_{n}$ is continuous because $i_{n}$ is also continuous. $i$ is one to one and $i(X)$ is dense in $X^{\prime \prime}$.

Let us consider the map restriction $\phi: C\left(X^{\prime \prime}\right) \rightarrow C(X) f \rightarrow f \circ i$.

(1) We have that $\phi\left(C\left(X^{\prime \prime}\right)\right)=C_{w b u}(E)$. Let us see it.

If $f \in C_{w b u}(E)$, it follows that $f_{n}=\left.f\right|_{B_{n}}: B_{n} \rightarrow R$ is weakly uniformly continuous. Then, by density, it can be extended to $\widetilde{f}_{n}$ : $B_{n}^{\prime \prime} \rightarrow R$ uniformly continuous, on the other hand,

$$
\left.\widetilde{f}_{n}\right|_{B_{n-1}^{\prime \prime}}=\tilde{f}_{n-1} \text { because }\left.\left(\left.\tilde{f}_{n}\right|_{B_{n-1}^{\prime \prime}}\right)\right|_{B_{n-1}}=\left.\left(\left.\tilde{f}_{n}\right|_{B_{n}}\right)\right|_{B_{n-1}}=\left.f_{n}\right|_{B_{n-1}}=f_{n-1}
$$

and

$$
\left.\widetilde{f}_{n-1}\right|_{B_{n-1}}=f_{n-1} \text {. }
$$

Then both functions are exactly the same over a dense part of $B_{n-1}^{\prime \prime}$ thus they are the same.

It can be defined $\tilde{f}: X^{\prime \prime} \rightarrow R$ continuous by $\tilde{f}(x)=f_{n}(x)$ if $x \in$ $B_{n}^{\prime \prime}$. Obviously $\left.\tilde{f}\right|_{x}=f$, thus $\left.f \in \phi\left(X^{\prime \prime}\right)\right)$.

Conversely if $f \in \phi\left(C\left(X^{\prime \prime}\right)\right)$ it follows that there exists $\tilde{f} \in C\left(X^{\prime \prime}\right)$ such that $f=\left.\tilde{f}\right|_{X}$; but $\widetilde{f}_{n}=\left.\widetilde{f}\right|_{B_{n}^{\prime}}$ is continuous on $B_{n}^{\prime \prime}$ which is compact. Then $\tilde{f}_{n}$ is uniformly continuous. Therefore $f_{n}=\left.f\right|_{B_{n}}$ is equal 
to $\left.\tilde{f}_{n}\right|_{B_{n}}$ and because of that, weakly uniformly continuous.

(2) $\phi$ is linear.

(3) $\phi$ is one to one because $i(X)$ is dense in $X^{\prime \prime}$.

(4) $\phi$ is continuous because the continuity of $i: X \rightarrow X^{\prime \prime}$ implies that the compacts of $X$ are compacts of $X^{\prime \prime}$.

On the other hand, the space $X^{\prime \prime}$ is a countable union of compacts and therefore the topology of $C\left(X^{\prime \prime}\right)$ is given by a countable family of semi-norms. Thus $C\left(X^{\prime \prime}\right)$ is metrizable. Because of the definition, $X^{\prime \prime}$ is a $k$-space and therefore $C\left(X^{\prime \prime}\right)$ is complete [11]; then $C\left(X^{\prime \prime}\right)$ is a Frechet space.

Since $C_{w b u}(E)$ is barreled it follows that $f$ is a topological isomorphism, applying the Open Mapping Theorem. Then it can be inferred that $C_{w b u}(E)$ is complete and therefore $E$ is reflexive.

Corollary 2.6. If $E$ is a Banach space, the following are equivalent:
(i) $E$ is reflexive
(ii) $C_{w b u}(E)$ is a Frechet space
(iii) $C_{w b u}(E)$ is a Ptak space
(iv) $C_{w b u}(E)$ is complete
(v) $C_{w b u}(E)$ is barreled
(vi) $C_{w b u}(E)=C_{v b}(E)$.

\section{REFERENCES}

1. H. H. Corson, The weak topology of a Banach space, Trans. Amer. Math. Soc, 101 (1961), 1-15.

2. J. Diestel, Geometry of Banach Spaces, Selected Topics. Lect. Notes in Math., 485 Springer-Verlag, New York, 1975.

3. J. Ferrera J. Gomez and J. L. G. Llavona, On completion of spaces of weakly continuous, functions, to appear in J. London Math. Soc.

4. L. Gilman and M. Jerison, Rings of Continuous Functions, Van Norstrand, 1960.

5. J. Kelley, General Topology, Springer.

6. G. Köthe, Topological Vector Spaces I, Springer-Verlag, New York, 1969.

7. L. Nachbin, Topological vector spaces of continuous functions, Proc. Nat. Acad. Sci. U.S.A., 40 (1954), 471-474.

8. T. Shirota, On locally convex vector spaces of continuous functions, Proc. Japan Acad., 30 (1954), 294-298.

9. M. Talagrand, Sur une conjecture de H. H. Corson, Bull. Sci. Math., (2), 99 (1975), 211-212.

10. M. Valdivia, Some new results on weak compactness, J. Functional Anal., 24 (1977), 1-10.

11. S. Warner, The topology of compact convergence on continuous function spaces, Duke Math. J., 25, 265-282.

Received June 17, 1981.

UNIVERSidad COMPLUTENSE

CiUdAd UNIVERsitaria

MadRID-3, Spain 



\section{PACIFIC JOURNAL OF MATHEMATICS}

\section{EDITORS}

DONALD BABBITT (Managing Editor)

University of California

Los Angeles, CA 90024

Hugo RossI

University of Utah

Salt Lake City, UT 84112

C. C. MOORE and ARThur Agus

University of California

Berkeley, CA 94720
J. DugundJI

Department of Mathematics

University of Southern California

Los Angeles, CA 90007

R. FINN and J. MILGRAM

Stanford University

Stanford, CA 94305

\section{ASSOCIATE EDITORS}
R. ARENS
E. F. BeCKENBACH
B. H. NeumanN
F. WOLF
K. YoSHIDA

\section{SUPPORTING INSTITUTIONS}

UNIVERSITY OF ARIZONA

UNIVERSITY OF BRITISH COLUMBIA

CALIFORNIA INSTITUTE OF TECHNOLOGY

UNIVERSITY OF CALIFORNIA

MONTANA STATE UNIVERSITY

UNIVERSITY OF NEVADA, RENO

NEW MEXICO STATE UNIVERSITY

OREGON STATE UNIVERSITY

\author{
UNIVERSITY OF OREGON \\ UNIVERSITY OF SOUTHERN CALIFORNIA \\ STANFORD UNIVERSITY \\ UNIVERSITY OF AAWAII \\ UNIVERSITY OF TOKYO \\ UNIVERSITY OF UTAH \\ WASHINGTON STATE UNIVERSITY \\ UNIVERSITY OF WASHINGTON
}

The Supporting Institutions listed above contribute to the cost of publication of this Journal, but they are not owners or publishers and have no responsibility for its content or policies,

Mathematical parers intended for publication in the Pacific Journal of Mathematics should be in typed form or offset-reproduced, (not dittoed), double spaced with large margins. Please do not use built up fractions in the text of the manuscript. However, you may use them in the displayed equations. Underline Greek letters in red, German in green, and script in blue. The first paragraph or two must be capable of being used separately as a synopsis of the entire paper. Please propose a heading for the odd unmbered pages of less than 35 characters. Manuscripts, in triplicate, may be sent to any one of the editors. Please classify according to the scheme of Math. Reviews, Index to Vol. 39. Supply name and address of author to whom proofs should be sent. All other communications should be addressed to the managing editor, or Elaine Barth, University of California, Los Angeles, California, 90024.

50 reprints to each author are provided free for each article, only if page charges have been substantially paid. Additional copies may be obtained at cost in multiples of 50 .

The Pacific Journal of Mathematics is issued monthly as of January 1966, Regular subscription rate: $\$ 114.00$ a year (6 Vol., 12 issues). Special rate: $\$ 57.00$ a year to individual members of supporting institution.

Subscriptions, orders for numbers issued in the last three calendar years, and changes of address shoud be sent to Pacific Journal of Mathematics, P.O. Box 969, Carmel Valley, CA 93924, U.S.A. Old back numbers obtainable from Kraus Periodicals Co., Route 100, Millwood, NY 10546.

\section{PUBLISHED BY PACIFIC JOURNAL OF MATHEMATICS, A NON-PROFIT CORPORATION}

Printed at Kokusai Bunken Insatsusha (International Academic Printing Co., Ltd.). 8-8, 3-chome, Takadanobaba, Shinjuku-ku, Tokyo 160, Japan. 


\section{Pacific Journal of Mathematics}

\section{Vol. 102, No. 2 \\ February, 1982}

Richard A. Boyce, Irreducible representations of finite groups of Lie type through block theory and special conjugacy classes ...............253

Robert Jay Daverman and Dennis J. Garity, Intrinsically

$(n-2)$-dimensional cellular decompositions of $E^{n} \ldots \ldots \ldots \ldots 275$

Juan Ferrera, Spaces of weakly continuous functions ................285

William George Frederick, $\mu$-theta functions ................... 293

Christopher George Gibson and T. D. Ward, On stratifying pairs of linear

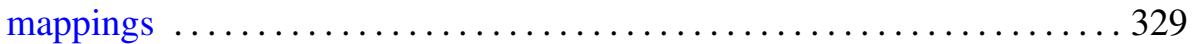

Stanley Joseph Gurak, Minimal polynomials for Gauss circulants and cyclotomic units ........................................ 347

Joachim Georg Hartung, On two-stage minimax problems ............. 355

Robert P. Kaufman, Hausdorff measure, BMO, and analytic functions . . . . 369

Neal I. Koblitz, $p$-adic analog of Heine's hypergeometric $q$-series . . . . . . . 373

Kurt Kreith, Picone-type theorems for hyperbolic partial differential

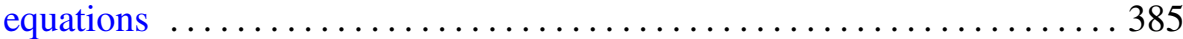

Nicholas J. Kuhn, The geometry of the James-Hopf maps ............. 397

Donald Michael Redmond, Explicit formulae for a class of Dirichlet

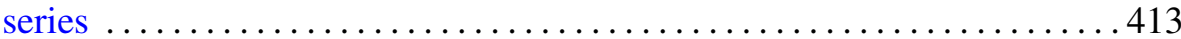

J. R. Respess and Elliott Ward Cheney, Jr., Best approximation problems in tensor-product spaces . .............................. 437

Allen Ross Schweinsberg, The operator equation $A X-X B=C$ with normal $A$ and $B$

Hans-Willi Siegberg and Guentcho Svetoslavov Skordev, Fixed point index and chain approximations

Kondagunta Sundaresan, Geometry and nonlinear analysis in Banach spaces 